\title{
LETTERS
}

\section{Starting cervical cancer screening at 25 years of age}

I am writing in regard to the CMAJ commentary by Popadiuk and colleagues ${ }^{1}$ on the starting age for cervical cancer screening. The authors did not mention the strength of the recommendation nor how it should be applied. In its 2013 guideline on screening for cervical cancer, the Canadian Task Force on Preventive Health Care recommended beginning screening at 25 years of age. ${ }^{2}$ The task force specified that this was a weak recommendation and screening should not be uniformly started at the age of 25 years. Instead, the decision of when to start screening, in women aged 2530 years, should be based on the risk and preferences of each woman. ${ }^{2}$

As a family physician in Alberta, I have many patients at low risk in this age group who have made the informed decision to wait until age 30 years for their first Papanicolaou smear. I feel it is particularly important to have this discussion, instead of routinely starting to screen at the age of 25 years, owing to the invasiveness and opportunity cost of the procedure.

In addition, I found it notable that only 2 provinces have updated their guidelines to align with the recommendations by the task force, as the 2013 guideline may need to be updated. Many jurisdictions, including the Netherlands, Italy, Norway, England, Australia and New Zealand, have changed or are in the process of changing to primary human papillomavirus screening with reflex cytology. The reasons cited for this change are increased sensitivity, less frequent screening intervals, decreased cost, and a projected decrease in incidence and mortality. ${ }^{3}$

\section{Roni Y. Kraut MD}

Family physician, University of Alberta, Edmonton, Alta.

- Cite as: CMAJ 2019 July 15;191:E797. doi: $10.1503 / \mathrm{cmaj} .72274$

\section{References}

1. Popadiuk C, Decker K, Gauvreau C. Starting cervical cancer screening at 25 years of age: the time has come. CMAJ 2019;191:E1-2.

2. Dickinson J, Tsakonas E, Conner Gorber S, et al.; Canadian Task Force on Preventive Health Care. Recommendations on screening for cervical cancer. CMAJ 2013;185:35-45.

3. Lew JB, Simms KT, Smith MA, et al. Primary HPV testing versus cytology-based cervical screening in women in Australia vaccinated for HPV and unvaccinated: effectiveness and economic assessment for the National Cervical Screening Program. Lancet Public Health 2017;2:e96-107.

Competing interests: None declared. 